\title{
COMPORTAMENTO MECÂNICO DE ARGAMASSAS DE CIMENTO PORTLAND FABRICADAS COM A ADIÇÃO DE FIBRAS DE SISAL MODIFICADAS POR ACETILIZAÇÃO*
}

Lucas Almeida Campos1 Evandro Tolentino ${ }^{2}$

Fernando Castro Oliveira ${ }^{3}$

\section{Resumo}

As fibras vêm sendo empregadas nos materiais de construção civil desde o início da humanidade. No começo da década de 50 houve o início da utilização de fibras de aço no reforço de matrizes de cimento. Com isso foram notadas alterações no comportamento do material, sendo detectado o aumento da tenacidade pós-fissuração. Esta é uma pesquisa experimental que teve como objetivo a definição de parâmetros de ensaios para a produção de argamassas de cimento Portland, que utilizem fibras de sisal nas suas composições, tratadas quimicamente por acetilização com intuito de reduzir a absorção de água. O sisal (Agave Sisalana) apresenta boas propriedades físicas e mecânicas. As fibras foram cortadas manualmente nos comprimentos de 20 $\mathrm{mm}$. As diferentes composições de argamassas foram produzidas com $0,2 \%$ e $0,4 \%$ de fibra de sisal, em relação ao volume total da argamassa. Estudou-se o comportamento mecânico dos compósitos com ensaios de resistência à tração na flexão. Os resultados mostraram uma melhoria na resistência à tração na flexão para argamassas com fibras tratadas quimicamente por acetilização.

Palavras-chave: Argamassa; Fibras; Sisal; Tração.

\section{MECHANICAL BEHAVIOR OF PORTLAND CEMENT MORTARS WITH CHEMICALLY MODIFIED SISAL FIBERS IN THEIR COMPOSITIONS}

\section{Abstract}

Fibers have been used in building materials since the beginning of mankind. At the beginning of the 50's steel fibers started being used as reinforcement in cement based matrices. It improved materials performance, increasing significantly the postcracking tenacity. The purpose of this research work was defining tests parameters for the production of Portland cement mortars with chemically modified sisal fibers in their compositions. Sisal fiber (Agave Sisalana) has outstanding physical and mechanical properties. Fibers were manually cut in lengths of $20 \mathrm{~mm}$. Different mortar compositions were produced with 0.2 and 0.4 of sisal fiber volume percent. Modulus of rupture of mortar specimens was evaluated. The tests results showed an improvement of modulus of rupture for mortars with chemically modified in their compositions.

Keywords: Mortar; Fibers; Sisal; Tension.

1 Engenheiro Civil, Mestrando em Engenharia Civil, UFV, Universidade Federal de Viçosa, Viçosa, Minas Gerais, Brasil.

2 Engenheiro Civil, Doutor em Engenharia Metalúrgica e de Minas, Professor, Departamento de Computação e Construção Civil-DCCTIM, CEFET-MG Campus VII Unidade Timóteo, Timóteo, Minas Gerais, MG, Brasil.

3 Químico, Doutor em Química, Professor, Departamento de Metalurgia e Química-DMQTIM, CEFET-MG Campus VII Unidade Timóteo, Timóteo, Minas Gerais, MG, Brasil. 


\section{INTRODUÇÃO}

As fibras vêm sendo utilizadas nos materiais de construção desde tempos remotos. Há evidências, na Babilônia e na Pérsia, da utilização de tijolos de adobe reforçados com fibras vegetais. No Egito existem também evidências de tijolos de barro feitos com argila cozida e reforço de palha seco ao sol. A construção civil conheceu os componentes laminares (de seção fina), a partir do século XVIII através de Ludwig Hatschek, que produziu placas de cimento e asbesto. O aperfeiçoamento desse processo de fabricação, denominado Hatschek, fez com que o cimento amianto (cimento + fibras de asbesto) se tornasse o principal produto laminado utilizado na construção civil, sob a forma de telhas, caixa d'água, painéis, etc. [1]. Entretanto, as fibras de asbesto foram proibidas em mais de 66 países devido a relatos de uma série de doenças respiratórias, tais como a asbestose (achado de fibras ou corpos de asbesto no tecido pulmonar) e o câncer pulmonar. A proibição incentivou a pesquisa de novas fibras. A dificuldade da substituição da fibra de asbesto esta associada às suas excelentes propriedades de resistência e à capacidade de reter finos do cimento. Além disso, o asbesto é quimicamente inerte, o que provê uma grande durabilidade quando exposto ao meio ambiente.

A utilização total ou parcial de fibras vegetais como substitutas de diversos produtos sintéticos tem apresentado um grande potencial de aplicação tecnológica. $O$ emprego de compósitos de matriz polimérica, reforçados por fibras naturais lignocelulósicas vem tendo um crescente desenvolvimento nos últimos anos. Muitas fibras naturais (celulose, madeira, juta, kenaf, abacaxi, coco, sisal, etc.) têm sido utilizadas como reforço em materiais compósitos [2]. O sisal é uma das fibras naturais mais utilizadas mundialmente, sendo o Brasil um dos maiores produtores. $O$ sisal tem apresentado uma série de vantagens que viabilizam a sua aplicação em várias indústrias do ramo automobilístico. Existe, também, o desenvolvimento de materiais plásticos reforçados com fibras de sisal para o uso na construção civil, como, por exemplo, em substituição de placas de madeira ou em formulação de argamassas.

Este trabalho consistiu em definir quantidades e parâmetros de ensaios para a produção de argamassa de cimento Portland com a adição de fibras de sisal modificadas quimicamente por acetilização em sua composição.

\section{MATERIAIS E MÉTODOS}

Os experimentos foram realizados no Laboratório de Materiais de Construção, do Centro Federal de Educação Tecnológica de Minas Gerais, Campus VII Únidade Timóteo. Foi utilizado nesta pesquisa o cimento Portland CP III 32 RS (equivalente ao norte americano ASTM type IS). O agregado miúdo utilizado foi a areia de rio quartzosa, comercializada na cidade de Timóteo, MG. As composições utilizadas para os corpos-de-prova cilíndricos foram estabelecidas de acordo com a norma NBR 7215:1996 [3]. As diferentes composições de argamassas foram produzidas com $0,2 \%$ e $0,4 \%$ de fibra de sisal, em relação ao volume total da argamassa. A Tabela 1 a seguir descreve as composições e quantidades utilizadas para a confecção de seis corpos-de-prova.

Tabela 1. Composições das argamassas utilizadas para a confecção de 6 corpos-de-prova.

\begin{tabular}{cccccc}
\hline Corpo-de-prova & $\begin{array}{c}\text { Areia } \\
(\mathbf{g})\end{array}$ & $\begin{array}{c}\text { Cimento } \\
(\mathbf{g})\end{array}$ & $\begin{array}{c}\text { Água } \\
(\mathbf{m l})\end{array}$ & $\begin{array}{c}\text { Fibra-02\% } \\
(\mathbf{g})\end{array}$ & $\begin{array}{c}\text { Fibra-0,4\% } \\
(\mathbf{g})\end{array}$ \\
\hline Prismático & $2.211,84$ & 737,28 & 353,89 & 5,85 & 11,70 \\
\hline
\end{tabular}


Uma das características encontradas nas fibras de sisal é a sua grande capacidade de absorção de água, ou seja, são fibras hidrofílicas, podendo, portanto, influenciar na cura da argamassa. Para modificar o caráter hidrofílico das fibras foi utilizado o método de acetilação com anidrido acético. Trata-se de um método que tem o objetivo de substituir as hidroxilas presentes nas fibras naturais, por grupos ésteres, diminuindo a polaridade e, portanto, a hidrofilicidade destas. Para maior eficiência da reação utilizou-se ácido forte para catalisar a esterificação [4]. O ácido acético foi usado com a finalidade de promover intumescimento das fibras, facilitando a penetração do anidrido acético. Esperava-se, com isso, um maior grau de esterificação das fibras.

Para o tratamento superficial das fibras, foram pesadas $50 \mathrm{~g}$ de fibra de sisal; posteriormente, as fibras foram transferidas para um reator de três bocas, junto com $250 \mathrm{ml}$ de anidrido acético, $250 \mathrm{ml}$ de ácido acético e 3 gotas do catalisador ácido nítrico $\left(\mathrm{HNO}_{3}\right)$ concentrado. $\mathrm{O}$ reator de condensação foi acoplado num banho termostático para que a reação ocorresse durante 4 horas, em uma temperatura aproximada de $80^{\circ} \mathrm{C}$. Logo após, as fibras foram submersas em água por aproximadamente 15 horas. Em seguida, as fibras foram lavadas 5 vezes com água destilada e depois aquecidas em estufa por 12 horas. A Figura 1 a seguir apresenta as fibras sisal após a acetilização.

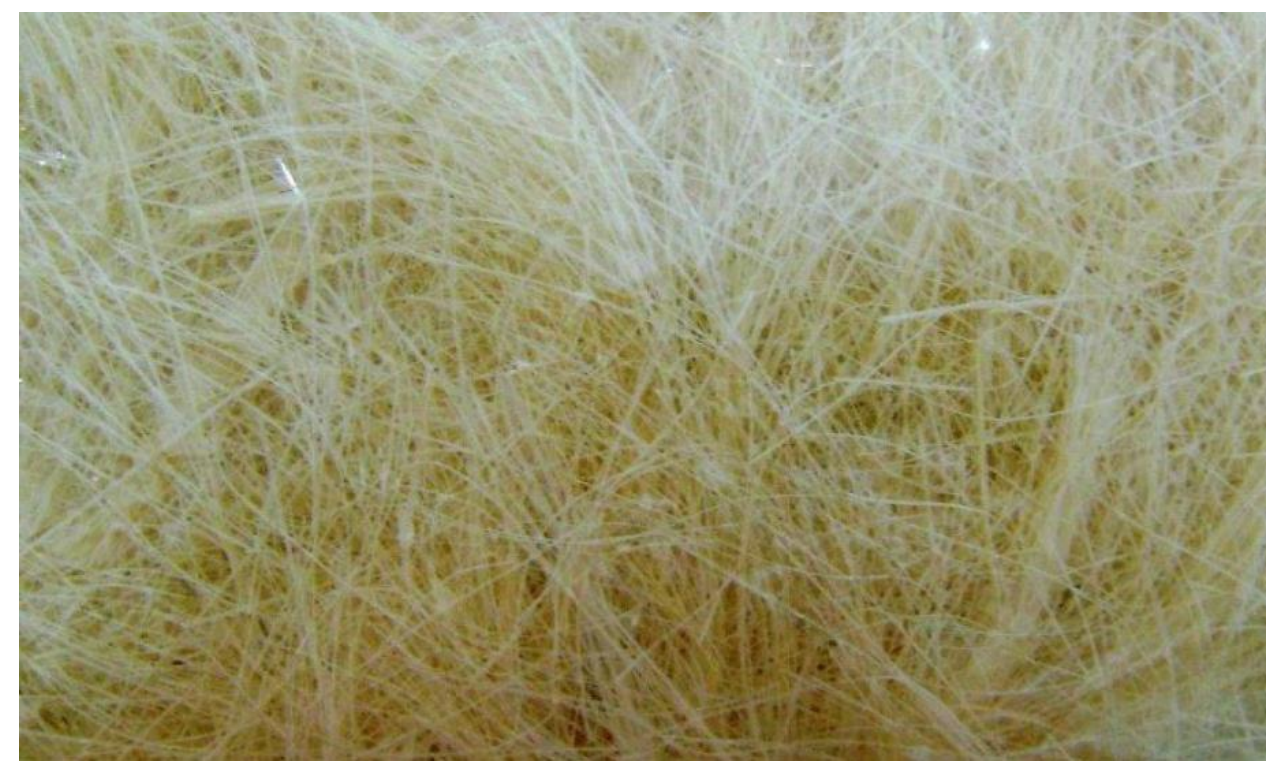

Figura 1. Fibras de sisal modificadas por acetilização.

Para os ensaios de tração na flexão foram confeccionados um total de 30 corpos-deprova prismáticos, de referência e com porcentagens de $0,2 \%$ e $0,4 \%$ de seu volume de fibras de sisal naturais e modificadas (6 corpos de prova prismáticos para cada condição).

As fibras foram cortadas com comprimento de $20,0 \mathrm{~mm}$. A moldagem seguiu o procedimento da NBR 5738:2003 [5] e o adensamento mecânico foi executado em duas camadas. Todos os corpos-de-prova moldados foram imersos em tanque de cura, após 24 horas de moldagem, e permaneceram neste estado até 24 horas antes da realização dos ensaios.

Os ensaios de resistência à tração na flexão (ver Figura 2) foram realizados após 28 dias. Foi utilizada uma prensa eletromecânica digital (Contenco l-3025B) com carga máxima de 100 toneladas. 


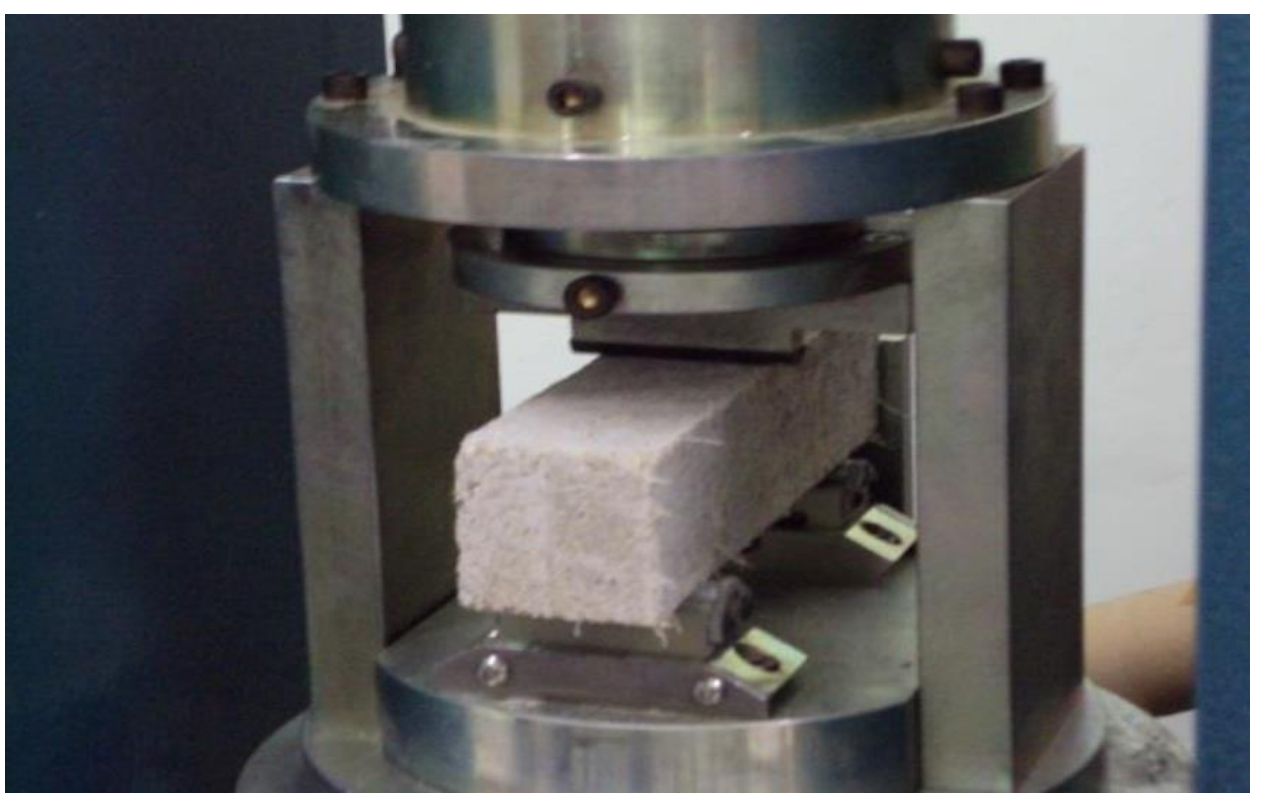

Figura 2. Ensaio de resistência à tração na flexão dos corpos-de-prova de argamassas.

\section{RESULTADOS E DISCUSSÃO}

Os ensaios para determinação de resistência à tração na flexão (módulo de ruptura) seguiram o procedimento da NBR 12142:1991 [6]. Por meio dos dados obtidos no ensaio de tração na flexão foram obtidos os gráficos com o auxilio do programa computacional Minitab®. Os gráficos mostram os efeitos no ensaio de tração na flexão de corpos-de-prova da adição de diferentes quantidades de fibras tratadas ou não em matriz de argamassa.

No gráfico apresentado na Figura 3 a seguir é ilustrada a média dos resultados de resistência à tração na flexão, após os 28 dias de moldagem. Observou-se que os resultados obtidos para os corpos-de-prova de referência (sem fibras) foram inferiores aos demais.

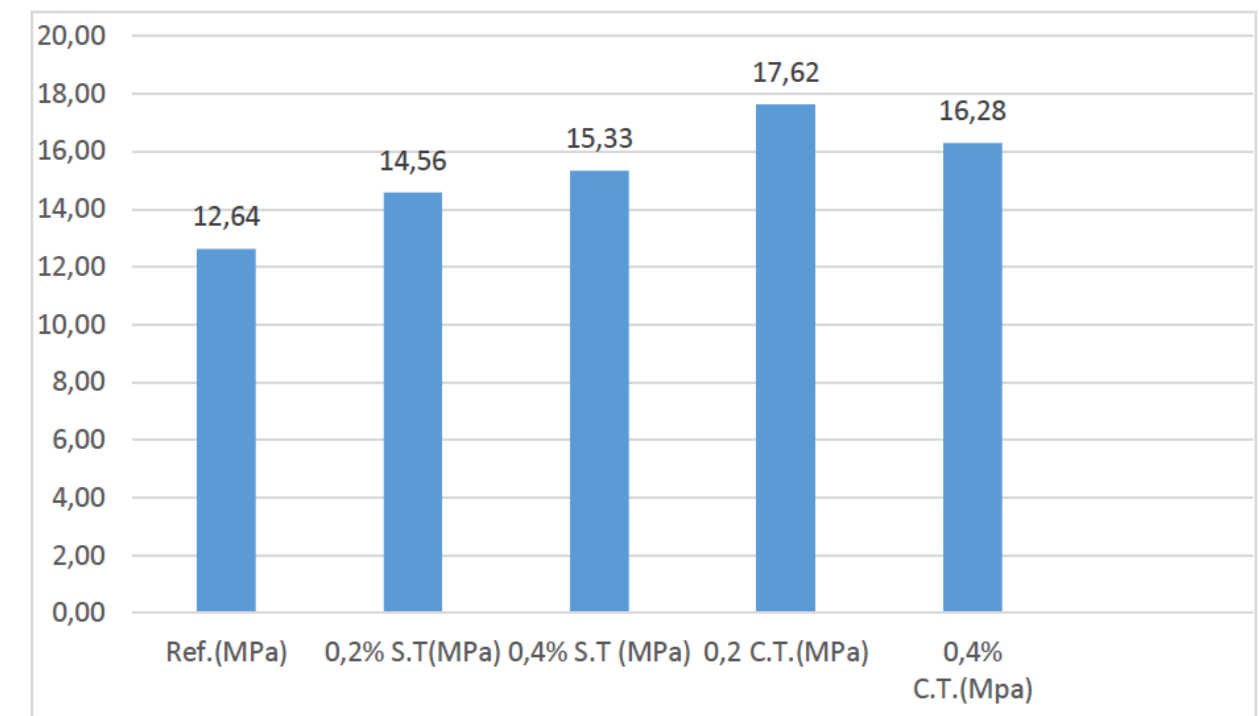

Figura 3. Resistência média à tração na flexão dos corpos-de-prova de argamassas. 
O gráfico de Pareto dos Efeitos Padronizados apresentado a seguir (ver Figura 4) mostra que todos os efeitos no qual ultrapassam a linha no valor de 1,725 são significantes. Desse modo, é perceptível que somente a interação entre a porcentagem de adição e o tratamento químico obteve efeitos estatisticamente significativos.

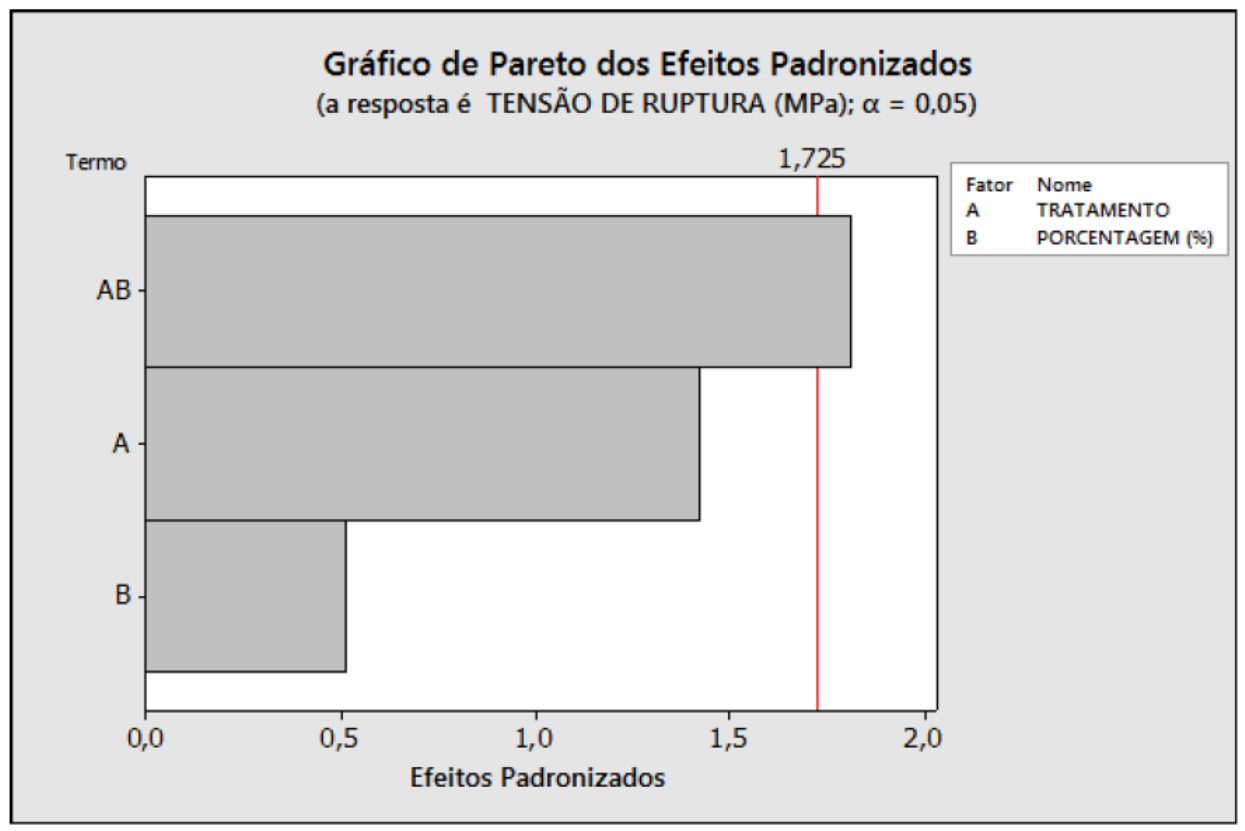

Figura 4. Gráfico de Pareto dos efeitos padronizados.

Contudo, o gráfico de Efeitos Principais apresentado a seguir (ver Figura 5) mostra uma melhora significativa quando analisados os efeitos provocados pelo tratamento químico de acetilização e pela alteração de porcentagem (\%) de fibras de sisal nos compósitos. Fica evidente que para a resistência à tração na flexão o tratamento de acetilização adotado para reduzir o caráter hidrofílico das fibras de sisal obteve resposta mais favorável. Também foi evidenciado um aumento na resistência a tração na flexão quando adicionado porcentagem de fibras de sinal tanto para $0,2 \%$ quanto para $0,4 \%$ em relação ao volume do corpo de prova. 


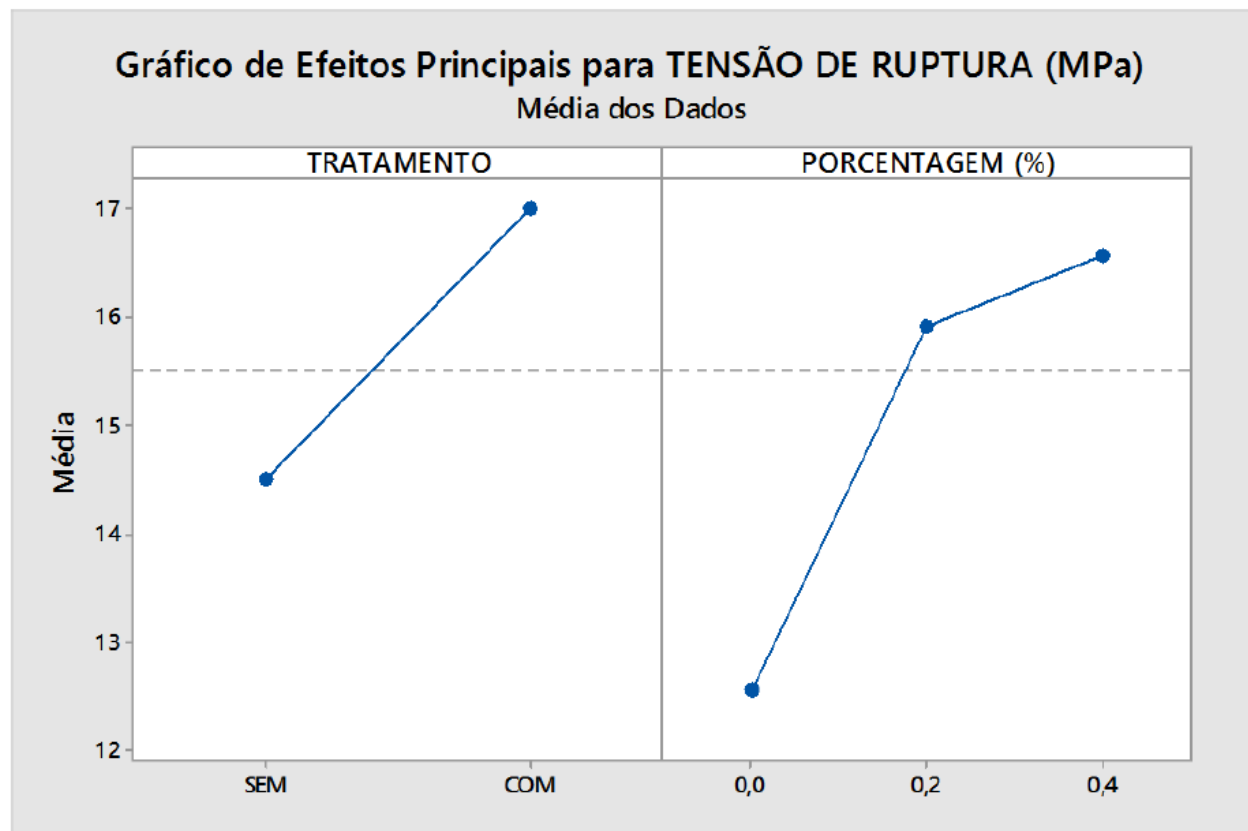

Figura 5. Gráfico de efeitos para tensão de ruptura por tração na flexão.

Com o objetivo de verificar qual composição de argamassa conseguiu os melhores resultados, foi necessário analisar a interação entre os resultados. Portanto, no Gráfico de Interação para Tensão de Ruptura (ver Figura 6) nota-se que a quantidade de $0,2 \%$ de fibras com tratamento obteve os melhores resultados deste experimento. Já para as fibras sem tratamento, a porcentagem de $0,4 \%$ de fibras obtiveram os melhores resultados. $\mathrm{O}$ aumento da proporção de fibras de sisal no compósito de argamassa proporcionou um ganho considerável na resistência à tração na flexão. No caso das fibras com tratamento o aumento da porcentagem provocou um efeito indesejável.

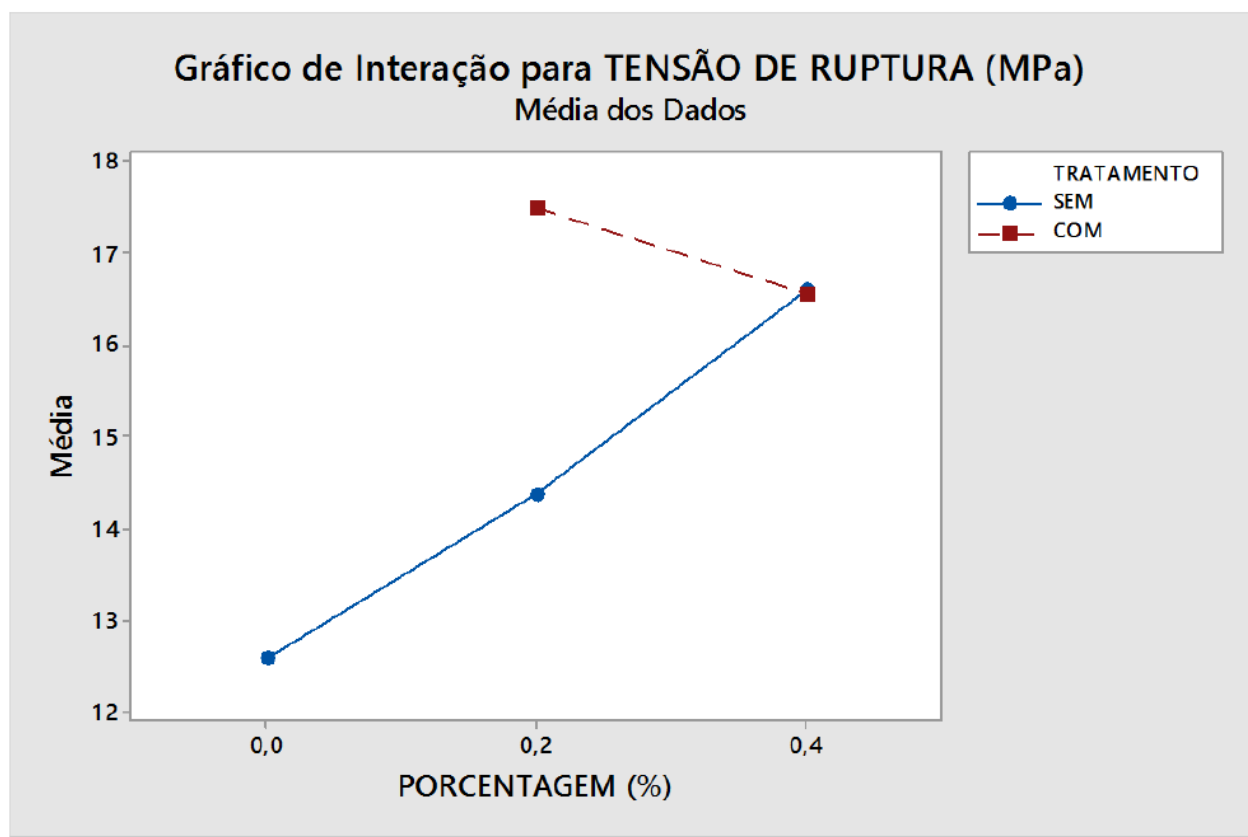

Figura 6. Gráfico de interação para tensão de ruptura por tração na flexão.

A Figura 7 a seguir mostra um corpo-de-prova prismático composto de argamassa e fibras de sisal logo após o seu rompimento. Ficou evidente que as fibras atuaram 
como ponte de transferência de tensão, já que as fibras ainda estavam trabalhando na união da peça, inibindo o aumento de fissuras de tração e cisalhamento, atuando, portanto, como "grampos" na fissura de tração provocada.

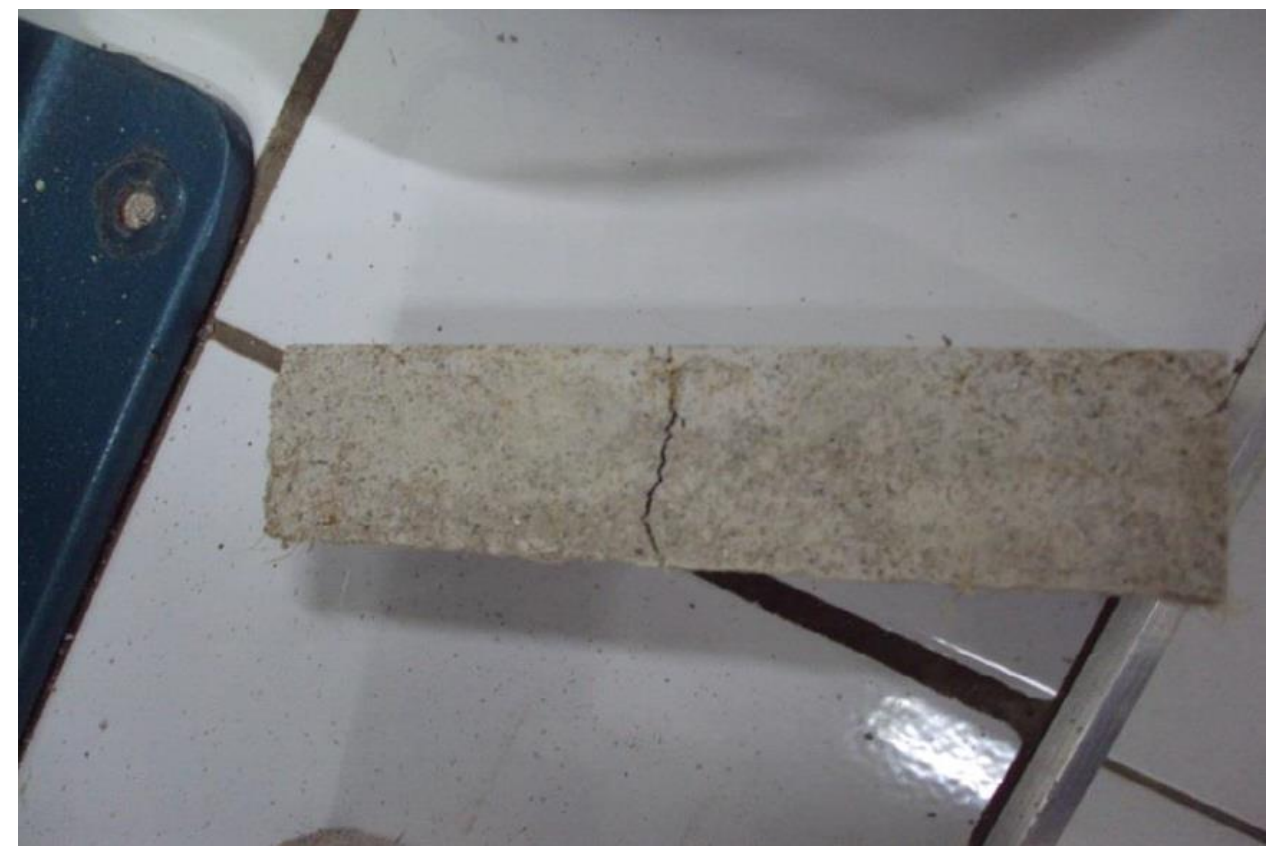

Figura 7. Corpo-de-prova logo após seu rompimento por tração na flexão.

\section{CONCLUSÃO}

Neste estudo foi possível constatar que, ao analisar corpos de prova submetidos a ensaios de tração na flexão, o aumento da porcentagem de adição e o tratamento de acetilização produziram resultados favoráveis. Os corpos-de-prova com $0,2 \%$ de seu volume composto por fibras tratadas obteve um aumento de $39,4 \%$ na sua resistência a tração, quando comparado a um corpo de prova sem fibra. $O$ tratamento químico obteve como resposta um aumento aproximadamente de $21 \%$ na resistência de matrizes cimentícias quando comparado com fibras sem tratamento químico.

O resultado mostra a importância do emprego das fibras de sisal em matrizes cimentícias, já que estas apresentam fragilidade quando submetidos à tração. Além de garantir uma melhor resistência à flexão e apresentar um comportamento mais elástico da estrutura, as fibras mostraram resistir melhor após a fissuração do corpo de prova, isto ocorreu devido às fibras estarem agindo como pontes de transferência de tensões, diminuindo assim as concentrações de tensões na extremidade das fissuras.

O trabalho mostra que a diferença na quantidade de fibras utilizadas é de grande importância para futuros estudos, bem como diferentes tratamentos químicos e traços.

\section{Agradecimentos}

Este trabalho contou com auxílios do Programa Institucional de Bolsas de Iniciação em Desenvolvimento Tecnológico e Inovação (PIBITI) que foi desenvolvido pelo Conselho Nacional de Desenvolvimento Científico e Tecnológico (CNPq), que foi 
realizado no período de agosto de 2013 a julho de 2014 referente ao edital $n^{0}$ 58/13 de 21 de maio de 2013.

\section{REFERÊNCIAS}

1 CUNHA SS. Perspectiva de utilização de materiais compósitos com fibras vegetais em habitações de interesse social [monografia de graduação]. Feira de Santana: Universidade Estadual de Feira de Santana; 2007.

2 FAVARO SL. Preparação e caracterização química, morfológica e de propriedades mecânicas de compósitos de polietileno pós-consumo com fibras de sisal e com cascas de arroz [dissertação de mestrado]. Maringá: Universidade Estadual de Maringá; 2007.

3 ASSOCIAÇÃO BRASILEIRA DE NORMAS TÉCNICAS. NBR 7215. Cimento Portland Determinação da resistência à compressão. Rio de Janeiro: ABNT, 1996.

4 Zafeiropoulos NE, Williams DS, Baillie CA, Matthews FL. Engineering and characterization of interface in flex fiber polypropylene composites materials. Part I: Development and investigation of surface treatments. Composites: Part A. 2002, 33: 1083-1093.

5 ASSOCIAÇÃO BRASILEIRA DE NORMAS TÉCNICAS. NBR 5738. ConcretoProcedimentos para moldagem e cura de corpos-de-prova. Rio de Janeiro: ABNT, 2003.

6 ASSOCIAÇÃO BRASILEIRA DE NORMAS TÉCNICAS. NBR 12142. Concreto Determinação da resistência à tração na flexão em corpos-de-prova prismáticos. Rio de Janeiro: ABNT, 1991. 